\title{
PREDICTORS OF EARLY RETURN TO WORK AFTER A CORONARY ARTERY BYPASS GRAFT SURGERY (CABG)
}

\section{RAMIN MEHRDAD ${ }^{1}$, NOROJA GHADIRI ASLI ${ }^{1}$, GHOLAMREZA POURYAGHOUB ${ }^{1}$, MARYAM SARAEI ${ }^{1}$, FIROOZEH SALIMI ${ }^{1}$, and MOSTAFA NEJATIAN ${ }^{2}$}

\author{
Tehran University of Medical Sciences, Tehran, Iran \\ ${ }^{1}$ School of Medicine, Department of Occupational Medicine, Centre for Research on Occupational Diseases \\ ${ }^{2}$ Tehran Heart Center, Department of Cardiac Rehabilitation
}

\begin{abstract}
Objectives: Identifying factors predictive of early return to work in patients who underwent a coronary artery bypass graft surgery $(\mathrm{CABG})$. Material and Methods: Two hundred twenty-six working patients who volunteered and underwent a primary coronary artery bypass surgery between September 2013 and May 2014 were selected for the study and followed up for 6 months. Predictors of early return to work (RTW) (within 2 months) were analyzed from variables in a prospectively collected database and the 36-Item Short Form Health Survey (SF-36) questionnaire carried out in the hospital and rehabilitation center as well as from the follow-up performed via the phone. Results: One hundred and two (45.1\%) and 155 (68.9\%) patients returned to work within 2 and 3 months after the surgery, respectively. Furthermore, 196 patients $(87.1 \%)$ returned to work within 6 months after the surgery. In the univariate analysis, demographic or socioeconomic factors (such as age, level of education, income), occupational factors (such as occupation type, working hours per week, duration of the preoperative absence from work), psychological factors (such as a patient's concern about adverse health effects of RTW, feeling depressed, a patient's attitude towards his/her ability to RTW and a patient's perception of his/her job stress level) and medical factors (such as serum troponin $\mathrm{T}$ and creatine kinase $\mathrm{MB}$ (CKMB) level, pump time in surgery, co-surgery and dyslipidemia history) had a statistically significant correlation with early return to work. The patients who early returned to work had significantly higher scores in 3 domains on the SF-36 questionnaire (used for assessing the patients' quality of life), compared to those who did not return to work early (including physical functioning, role limitations due to physical health and pain). Conclusions: In the present study we identified 4 new medical factors that could be used as predictors of early return to work after CABG. These factors are: normal serum troponin T level, shorter pump time in surgery, normal mean arterial pressure (MAP) before the surgery and higher serum magnesium (Mg) levels. Int J Occup Med Environ Health 2016;29(6):947-957
\end{abstract}

Key words:

Quality of life, Rehabilitation, Return to work, Predict, Coronary artery bypass graft, CABG

\section{INTRODUCTION}

Current global rise in coronary artery diseases (CAD) which can be observed among people from every ethnic group, is a result of industrialization and lifestyle changes all over the world [1]. Nowadays, most of patients suffer from $\mathrm{CAD}$ in their most productive years of life, before reaching retirement age. Many of such patients resign from work voluntarily or due to an employer's policy earlier than the retirement time [2]. The rate of age-adjusted mortality for CAD is $25-40 \%$ [3]. However, in a research

Funding: the work is financially supported by Tehran University of Medical Sciences, grant No. 24355. Grant manager: Ramin Mehrdad, M.D., M.P.H. Received: September 13, 2015. Accepted: December 14, 2015.

Corresponding author: N. Ghadiri Asli, Tehran University of Medical Sciences, School of Medicine, Department of Occupational Medicine, Centre for Research on Occupational Diseases, 16 Azar Street, Enqelab Square 1417613151 Tehran, Iran (e-mail: dr.nghadiri@yahoo.com). 
conducted on 3723 random samples in Iran, it has been found that $11.3 \%$ of cases had coronary symptoms and additional $1.4 \%$ had myocardial infarction (MI). Therefore, the age-adjusted prevalence in this study was $12.7 \%$ [4]. Current therapeutic approaches have led to a decline in CAD mortality rates. One of these approaches is coronary artery bypass grafting (CABG). Coronary artery bypass grafting is performed for the purpose of treating CAD symptoms, regaining normal functioning and good quality of life [2].

Coronary artery bypass grafting is more complex than other methods of revascularization, such as percutaneous transluminal coronary angioplasty (PTCA), but it is considerably safe. Recovery is quick and most of the patients return to their work within 2-3 months after the surgery. Moreover, most of patients with angina get well after the surgery $[5,6]$. Patients who were working before the surgery could do the same job with no restrictions. Unfortunately, the surgery is often a dramatic event that may result in an overprotective attitude among family, friends, employer and even medical advisors. As a result, most of people who have the ability to work and should return to work, do not do so. Moreover, because of a long waiting list for the angiography and bypass surgery many of the patients lose their jobs so there is no job for them to return to [5]. According to one study, the ratio of returning to work amongst patients who lost their job within more than 6 months before the surgery was less than amongst those who lost their job in less than 6 months (35\%) [7]. Condition of no restrictions is necessary after returning to work. Graft occlusion causes angina recurrence with less severity than before in a rate of $4 \%$ per year but still affects the long term occupational plan. Although return to work (RTW) after angioplasty is quicker than after CABG, long term employment perspective is equal in both [5]. Evidently, an individual who has got his functions back is expected to be able to do his normal day to day activities and, in particular, to be able to return to work. Obviously, economic productivity of such patients within approximately 15 more years of work will compensate for a big portion of their operation cost. But reality looks different. Various studies have shown that in spite of a full or partial recovery from angina and an increased functional exercise capacity in most patients, only $50-84 \%$ of them returned to work after the surgery [8].

In a study conducted in Iran [9] as well as in another study [10], CABG has been identified as one of the most important predictor factors of failure in returning to work after the first myocardial infarction. This could be due to the existing correlation of RTW with factors other than the surgery success. According to some other studies [11-19], psychologic and socioeconomic factors play a more potent role in returning to work after coronary events and $\mathrm{CABG}$ than medical factors themselves. Some of these prognostic factors can be also modified. Nevertheless, so far there is no evidence that a prognostic factor can change prognosis of work ability, just because it is modifiable. Currently, such factors can only be applied as a flag or an index for a prognosis [20]. On the other hand, RTW itself can improve the quality of life and economical security of patients and their families [18,21]. Moreover, according to previous studies, the longer absence from work, the smaller the probability of return to work $[6,22]$ - absence from work for 12 weeks, can reduce the probability of RTW by $50 \%$ [23]. That reflects importance of early return to work.

Considering the prevalence of $\mathrm{CAD}$ and its incidence at a young age, it is obvious that failure in returning to work can result in many lost work days (LWD). Therefore, ability to return to work is an important aspect of the treatment procedure of CAD patients, and that is only achievable through the perfect coordination between a patient and a doctor. Identifying factors that may facilitate return to work can help create such an effective coordination. Several studies have been conducted on the factors that affect a patient's return to work after CAD and medical 
procedures including CABG. Several predictors for return to work after the surgery have been presented, including: age, self-perceived vocational disability, a physician's perception of a patient's disability, expectations regarding work, duration of the preoperative absence from work, functional class, a patient's perception of working capacity 6 months after $\mathrm{CABG}$, education, job satisfaction, gender (female or male), physical pattern of work, severity of heart failure, white-collar or blue-collar occupation, preoperative employment, non-cardiovascular illnesses, duration of symptoms, participation in a cardiac rehabilitation program (CRP), immigration status, academic profession, etc. [2,8,12,17,19,24-30].

However, further and more robust evidence is still required to demonstrate work ability prognostic factors for these patients. Also social, political and demographic environments have an impact on making decisions for patients to resume their previous job, change the job or retire. Studies on the return to work after acute myocardial infarction (AMI) show large differences among different countries. Part of these discrepancies is related to the differences concerning the time of follow-up, patients' age groups and respective insurance [31]. Therefore, this study with the aim of identifying factors predictive of return to work following a CABG surgery, was designed and conducted at Tehran Heart Center, one of the major academic centers affiliated to the Tehran University of Medical Sciences in Iran.

\section{MATERIAL AND METHODS}

All eligible patients referred to Tehran Heart Center for the coronary artery bypass graft $(\mathrm{CABG})$ between September 2013 and May 2014 (248 patients) were asked to participate in this study. Inclusion criteria as well as an informed consent were applied before hospitalization. Sixteen of the selected patients who were to have the surgery but who cancelled or postponed it due to unconfirmed medical conditions or other reasons, were excluded from the study. Moreover, 4 patients who did not answer the follow-up call as well as 2 patients who died before completion of the 2 months period after the operation and before they returned to work, were excluded from the study. Eventually, 226 patients were included in the study. All the selected patients were informed about the study objectives and a consent form was signed by them individually.

A form consisting of demographic, socioeconomic and psychological information as well as medical and occupational history was completed for each patient upon arrival at the hospital. The patients were also evaluated in terms of routine clinical laboratory test results, including: total cholesterol, low-density lipoprotein (LDL), high-density lipoprotein (HDL), triglyceride (TG), and glycated hemoglobin $\left(\mathrm{HbA}_{1 \mathrm{C}}\right)$. Furthermore, a patient's cardiac status, including: echocardiography and electrocardiography (ECG) results, cardiac markers enzymes, presence and severity of symptoms, history of cardiovascular diseases, history of cardiovascular intervention, etc., was assessed before the operation.

Information on occupational history was collected in details. Based on these data, the study individuals were classified in major occupational groups (Agriculture, Forestry and Fishing, Transportation, Sales, Official and Educational, Industrial, Services, Managing). Additionally, the patients were categorized as white-collar and bluecollar workers using Australian Standard Classification of Occupations guidelines. Moreover, by estimating physical activity and based on resources such as United States Department of Health and Human Services (USDHHS) [32], the patients were classified as employed in light, moderate and strenuous jobs. Moreover in the questionnaire, the patients answered questions whether their job is stressful or not.

In addition to the above mentioned questions, the 36-Item Short Form Health Survey (SF-36) questionnaire was filled in so as to assess the patients' quality of life. Moreover, the second patient information form containing surgery information (including a surgeon's name, time and 
duration of the surgery, pump time, cross-clamp time, side effects as well as duration of hospitalization) was completed after the operation. It should be noted that in this study early RTW is defined as "returning to work (both at fulltime or at reduced working hours) within the first 2 months after CABG." The follow-up of the study patients was performed by phone within 1 and 2 months after the surgery. The patients were asked about their return to work, working hours, physical demands and possible job changes after returning to work as well as cardiovascular symptoms, side effects, etc.

After data collection, the data were sorted into a database. The independent sample t-test was applied to compare mean of quantitative variables with normal distribution between the 2 groups with and without early return to work. In the case of non-normal distribution we used the Mann-Whitney U test. Also the Chi ${ }^{2}$ test was used to compare qualitative variables between these 2 groups of patients. Then, the logistic regression analysis was performed in order to find predictors of early RTW. P values $<0.05$ were considered as statistically significant.

\section{RESULTS}

There were only 2 female patients among the study population. The age range was $35-80$ years $(54.23 \pm 8.93$ years in average). Overall, $64.2 \%$ of the cases were $\leq 60$ years old. In terms of education, the cases had study records from 5 to 20 years. The mean education level was about 9 years. Approximately, 95\% of the patients were from urban areas, while the rest were from rural regions. There was a statistically significant difference in the univariate analysis results of early return to work between different major job groups.

The average weekly working hours of the patients before the operation was 54.42 (standard deviation $(\mathrm{SD})=21.93$ ). Of all the patients $102(45.1 \%)$ of them returned to work within 2 months after the surgery, of which 28 (12.4\%) returned to work within the first month. The 6-month follow-up of the patients showed that 196 (87.1\%) of the cases returned to work within 6 months after the operation. In order to study the early return to work predictors, different variables were evaluated among the 2 patient groups: those with early RTW and those without early RTW. The variables that showed statistically significant association in the univariate analysis, were divided into 4 groups, including: socioeconomic and occupational factors, psychological factors, medical factors and quality of life factors. The related subgroups are presented in Table 1. Near 1/3 (29.2\%) of the patients reported their jobs as stressful. The rate of early RTW was significantly higher among them. There were no statistically significant differences between the 2 groups in the univariate analysis of other variants studied in this research, including: working hours, economic need to work, pension insurance and employment status, a patient's desire to RTW, job satisfaction, pack-year in smokers, co-non-cardiovascular morbidity, co-vascular morbidity, previous MI history, intervention history, number of risk factors, cigarette smoking, opium use, body mass index (BMI), history of diabetes, hypertension, family history of coronary artery disease, symptomatic duration, mean arterial pressure (MAP), creatinine phosphokinase (CPK), lactate dehydrogenase (LDH), magnesium $(\mathrm{Mg})$, ejection fraction $(\mathrm{EF})$, functional class of angina, recent myocardial infarction (MI), pre-CABG abnormality in rest ECG, number of affected vessels, number of grafted vessels, surgery duration, cross clamp time, hospitalization, post-surgery hospital stay, in hospital complications and post or arrhythmia in hospital, cardiac complaints and their severities, medicine complication and family encouragement within 2 months after CABG. We used the logistic regression analysis to find the best model for prediction of early RTW. Predictors of early RTW are shown in Table 2. The early return to work predictors are categorized in Table 3. The date of RTW was defined via the follow-up phone and the interval between the surgery and RTW was presented in days. It was found that this time 


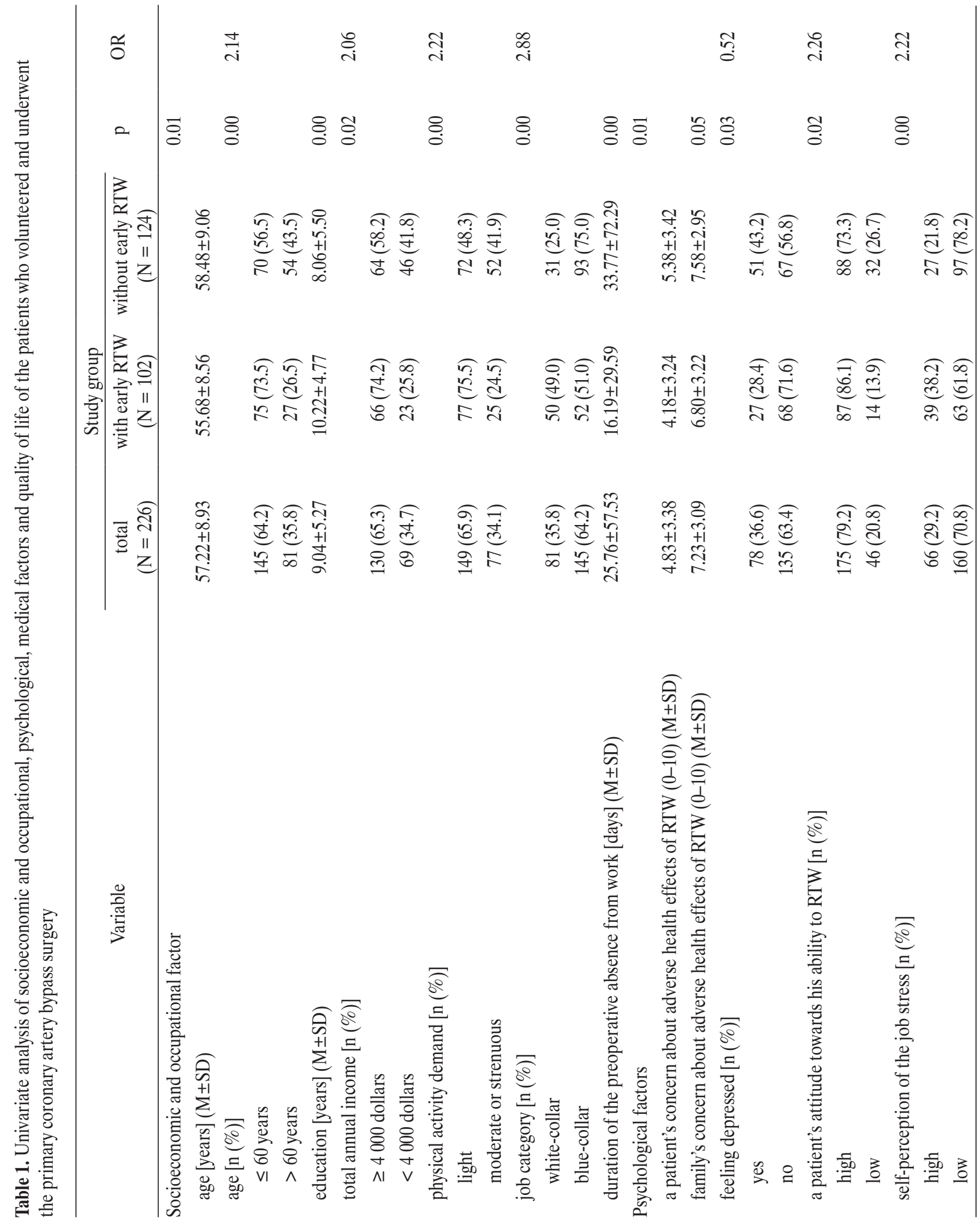




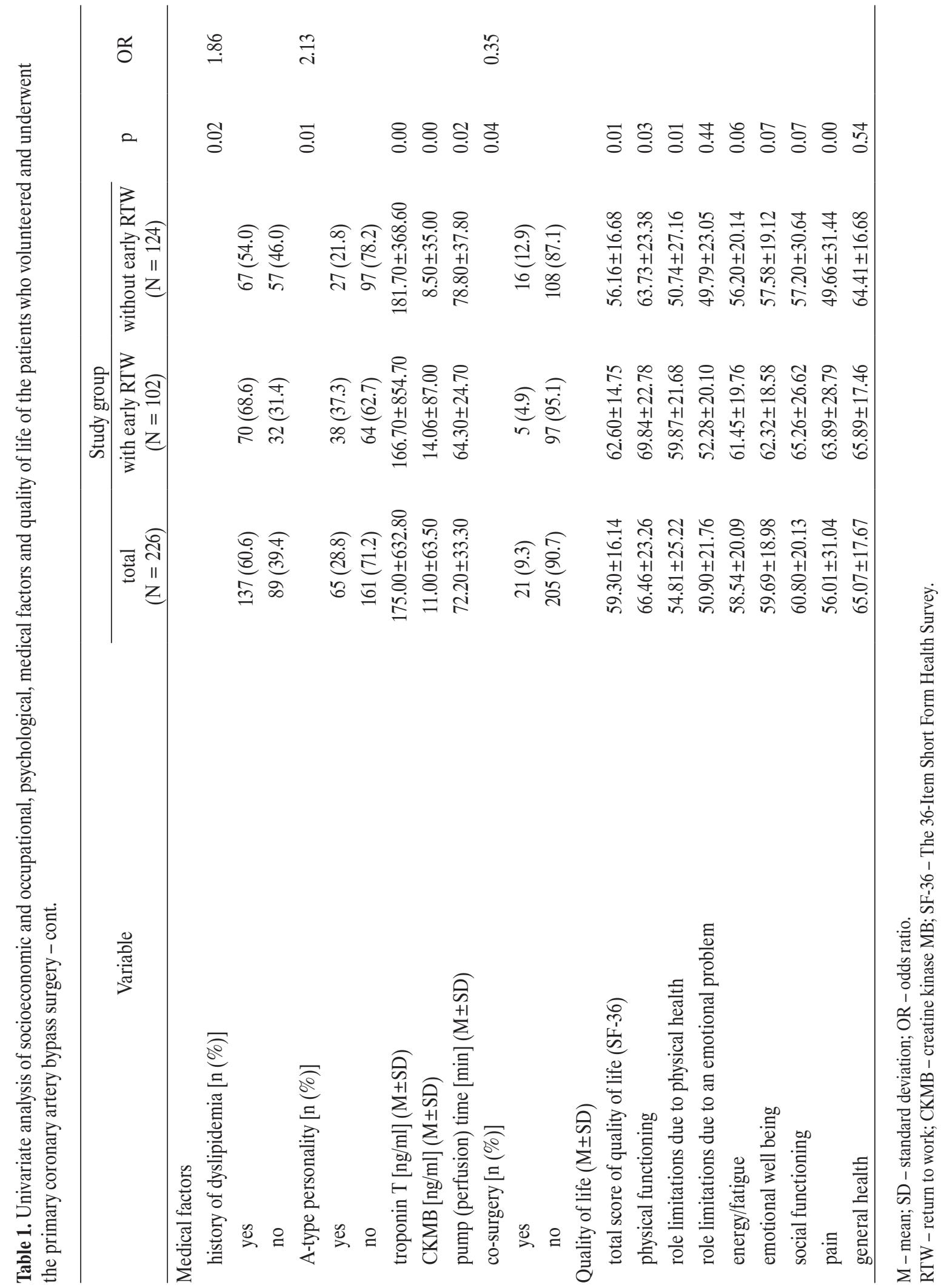


interval had a positive correlation with some of the quantitative studied variants, including: age, duration of the preoperative absence from work, a patient's concerns about adverse health effects of RTW, family's concerns about adverse health effects of RTW, creatine kinase MB (CKMB) (ng/ml), troponin T (ng/ml), pump time (min), cross clamp time (min). At the same time, the time interval had a negative correlation with variants including: education (year), total annual income (in dollars), pre-operation desire to RTW, a patient's perception of his ability to RTW.

In this study, RTW was defined as returning to work (both at full time and at reduced working hours). However, the post operation work details, such as: number of working hours and physical demands of work, after the surgery were also assessed. A comparison of the number of working hours before and after the surgery using the paired t-test in the patients who returned to work within 6 months, showed a statistically significant decrease in the average of working hours after the operation. It was found that $40(20.4 \%)$ patients had an increase and $127(64.8 \%)$ patients had a decrease in the number of working hours after the operation. Simultaneously, $28(14.8 \%)$ cases had no change in the number of working hours after the surgery. However, there was no statistically significant difference in the numbers of working hours between those with and without early RTW.

Table 2. Multivariate analysis of variables predicting early return to work after coronary artery bypass graft (CABG)

\begin{tabular}{llcc}
\hline \multicolumn{1}{c}{ Variable } & OR & $95 \%$ CI & $\mathrm{p}$ \\
\hline Industrial occupations & 0.13 & $0.03-0.57$ & 0.01 \\
Feeling depressed before CABG & 0.36 & $0.14-0.90$ & 0.03 \\
Duration of the preoperative absence from work & 0.92 & $0.87-0.97$ & 0.00 \\
Troponin T level & 4.27 & $1.54-11.87$ & 0.00 \\
Pump time in surgery [min] & 0.98 & $0.96-0.99$ & 0.00 \\
Hospital stay duration & 1.12 & $1.02-1.24$ & 0.02 \\
MAP $\leq$ 90 mm Hg & 3.40 & $1.22-7.83$ & 0.01 \\
Total annual income $\geq$ 4 000 dollars & 3.09 & $1.15-8.31$ & 0.02 \\
Patients perception of the ability to return to work & 3.81 & $1.13-12.81$ & 0.03 \\
Self-perception of the job stress & 2.30 & $1.01-8.87$ & 0.04 \\
Job category (not blue-collar) & 2.25 & $1.18-4.26$ & 0.01 \\
Serum Mg level & 7.24 & $0.91-58.11$ & 0.05 \\
$\mathrm{R}^{2}$ & & 0.53 & \\
\hline
\end{tabular}

MAP - mean arterial pressure; $\mathrm{Mg}$ - magnesium; $\mathrm{R}^{2}$ - coefficient of determination.

OR - odds ratio; $\mathrm{CI}$ - confidence interval.

Table 3. Predictors of early return to work after coronary artery bypass graft (CABG)

\begin{tabular}{lll}
\hline \multicolumn{1}{c}{$\begin{array}{c}\text { Socioeconomic } \\
\text { and occupational predictors }\end{array}$} & \multicolumn{1}{c}{ Psychological factors } & \multicolumn{1}{c}{ Medical factors } \\
\hline Not having industrial occupations & Not feeling depressed before CABG & Normal troponin T level \\
Not being a blue-collar worker & A patient's perception of his/her high & Shorter pump time in surgery [min] \\
Total annual income $\geq 4$ 000 dollars & ability to return to work & Shorter hospital stay duration \\
$\begin{array}{l}\text { Shorter duration of the preoperative } \\
\text { absence from work }\end{array}$ & $\begin{array}{l}\text { A patient's perception of a high level } \\
\text { of job stress }\end{array}$ & MAP $\leq 90 \mathrm{~mm}$ Hg before the surgery \\
\hline
\end{tabular}

Abbreviations as in Table 2. 


\section{DISCUSSION}

In this study, the percentage of early return to work was $45.1 \%$ and $87.1 \%$ within 2 months and 6 months, respectively. Younger age has been introduced as a predictor of RTW in several studies [12,17,24-29]. However, in this study, despite a significant association between the younger age (especially under 60) and early return to work, in the univariate analysis, the association of age was not statistically significant in the suggested model of logistic regression analysis. In the above mentioned studies, cases who were unemployed before the operation, were also involved in the study. In the current study, all the cases were employed before the surgery and if a patient was temporarily away from work prior to the surgery, it was due to a medical condition leading to $\mathrm{CABG}$ or because of the treatment process. Therefore, those who were older but were employed before the surgery, returned to work within 2 months after the operation. Consequently, older age was not a barrier to early return to work of those patients. The reason why age was not considered as a predictor in this study was that all the cases had employment and work ability before the CABG operation. It should be noted that there are different protocols for retirement in Iran. In Iran, age, years of work, health condition, difficulty level of work and extended self-employment are the most important factors determining time of retirement and in our study many individuals, even older than those at the retirement age, were still employed because of the above mentioned factors.

At the time of our study, poverty threshold in Iran was equal to the annual income of 4000 dollars. According to our study results, the individuals who had annual income $<4000$ dollars and were considered below the poverty threshold, had later return to work. In addition to the total annual income, factors, such as: not being a blue-collar worker, shorter duration of preoperative absence from work, not feeling depressed before $\mathrm{CABG}$, a patient's perception of his/her ability to RTW and shorter hospital stay duration, were considered as early RTW predictors. These factors have been also identified as RTW predictors in previous studies [2,12,17,26,30]. In addition to the above mentioned factors, there are some other factors, identified as early RTW predictors in this study. In the present study, factors, such as: having industrial occupations, normal serum troponin $\mathrm{T}$ level when admitted to the hospital, shorter pump time during $\mathrm{CABG}$, mean arterial pressure (MAP) $\leq 90 \mathrm{~mm} \mathrm{Hg}$ before the operation and higher serum magnesium level before the surgery, were identified as the predictors of early return to work. According to the literature review, hypomagnesemia is suggested as a risk factor for the development of postoperative atrial fibrillation $(\mathrm{AF})$ and other supraventricular or ventricular tachycardia [33]. However, in this study, there was no significant association between the serum magnesium level and early RTW in the univariate analysis. Similarly, the incidence of arrhythmia after the surgery was neither significantly associated with the preoperative serum magnesium level nor the early return to work. Moreover, there was no statistically significant association between the serum magnesium level and the incidence of heart palpitation in the first 2 months after the surgery. However, according to the suggested model of logistic regression, there was a significant borderline association between the higher serum magnesium level and early return to work.

In the present study, although there was no significant association between having/not having MI and early RTW, the patients with normal troponin $\mathrm{T}$ levels had higher early RTW possibility. Normal troponin T level can be a reflection of cardiovascular health. Furthermore, among the patients who returned to work within 6 months after the surgery, those with higher troponin T levels at the time of hospital admission had later RTW.

Shorter pump time in surgery (not the total operation time) was another predictor factor of early RTW in this 
study. Considering the day of return to work in the patients who returned to work within 6 months, showed that the longer pump time in the surgery, the later return to work. History of hypertension was not significantly associated with early RTW. However, normal ( $\leq 90 \mathrm{~mm} \mathrm{Hg}$ ) mean arterial pressure (MAP) before the surgery was identified as an early RTW predictor.

In this study, it was found that not having industrial occupations was a predictor of early RTW. This could be due to the higher energy demand in such occupations. In other studies $[25,26,28]$ gender has been significantly associated with RTW, but in this study the association of gender could not be evaluated, because the majority of the study cases were men.

Higher education has been considered as a RTW predictor in a number of studies [2,24]. However, in the present study the association of higher education was no longer significant in the suggested model of logistic regression. Being employed before the surgery was another RTW predictor [8,27] that could not be evaluated in this study since all the study cases were employed. However, duration of preoperative absence from work was inversely associated with the probability of early return to work, and directly associated with the time interval between the surgery and return to work (in days). In Fiabane et al.'s study (2013), in contrast to our study, job satisfaction was identified as a predictor of early return to work after CABG [19]. The reason may be that in the Fiabane et al.'s study, occupational stress indicator (OSI) was used in order to evaluate job satisfaction, while in the current study, visual analogue scale was used for the same purpose. Similarly, in Simchen et al.'s study (2001), cardiac rehabilitation program (CRP) was identified as a predictor of RTW [28]. In the present study, in spite of participation of $56 \%$ of the patients in cardiac rehabilitation programs, there was no statistically significant association between full or partial participation in the CRPs and early RTW.

\section{CONCLUSIONS}

In the present study we identified 4 new medical factors that could be used as predictors of early return to work after CABG. These factors are: normal serum troponin $\mathrm{T}$ level, shorter pump time in surgery, normal mean arterial pressure (MAP) before the surgery and higher serum $\mathrm{Mg}$ levels.

\section{ACKNOWLEDGMENTS}

We express our gratitude for the financial support of Tehran University of Medical Sciences. Greatly acknowledged for their contributions on the project are also the Centre for Research on Occupational Diseases (CROD) and Deputy of Research of Tehran Heart Center being the part of the University.

\section{REFERENCES}

1. Gaziano TA, Gaziano JM. Epidemiology of cardiovascular disease. In: Longo DL, Fauci AS, Kasper DL, Hauser SL, Jameson JL, Loscalzo J, editors. Harrison's principles of internal medicine. 18th ed. New York: The McGraw-Hill Companies, Inc.; 2012. p. 1811-6.

2. Danchin N, David P, Bourassa MG, Robert P, Chaitman BR. Factors predicting working status after aortocoronary bypass surgery. Can Med Assoc J. 1982;126(3):255-60.

3. Mann DL, Zipes DP, Libby P, Bonow RO. Braunwald's heart disease: A textbook of cardiovascular medicine. Toronto: Elsevier Canada; 2015.

4. Nabipour I, Amiri M, Imami SR, Jahfari SM, Shafeiae E, Nosrati A, et al. The metabolic syndrome and nonfatal ischemic heart disease; a population-based study. Int J Cardiol. 2007;118(1):48-53, http://dx.doi.org/10.1016/j.ijcard. 2006.06.017.

5. Palmer KT, Hobson IBJ. Fitness for work: The medical aspects. New York: Oxford University Press; 2013.

6. Skinner JS, Farrer M, Albers CJ, Neil HA, Adams PC. Patientrelated outcomes five years after coronary artery bypass graft surgery. QJM. 1999;92(2):87-96, http://dx.doi.org/10.1093/ qjmed/92.2.87. 
7. Nagle R, Gangola R, Picton-Robinson I. Factors influencing return to work after myocardial infarction. Lancet. 1971;2(7722):454-6, http:/dx.doi.org/10.1016/S0140-6736(71) 92627-4.

8. Pinto N, Shah P, Haluska B, Griffin R, Holliday J, Mundy J. Return to work after coronary artery bypass in patients aged under 50 years. Asian Cardiovasc Thorac Ann. 2012; 20(4):387-91, http://dx.doi.org/10.1177/0218492312437881.

9. Attarchi M, Mirzamohammadi E, Mohammadi S. Assessment of the main factors influencing return to work following myocardial infarction: A longitudinal study. Int J Collab Res Intern Med Public Health. 2012;4(6):1305-14.

10. McBurney CR, Eagle KA, Kline-Rogers EM, Cooper JV, Smith DE, Erickson SR. Work-related outcomes after a myocardial infarction. Pharmacotherapy. 2004;24(11):1515-23, http://dx.doi.org/10.1592/phco.24.16.1515.50946.

11. Mark DB, Lam LC, Lee KL, Clapp-Channing NE, Williams RB, Pryor DB, et al. Identification of patients with coronary disease at high risk for loss of employment. A prospective validation study. Circulation. 1992;86(5):1485-94, http://dx.doi.org/10.1161/01.CIR.86.5.1485.

12. Mittag O, Kolenda KD, Nordman KJ, Bernien J, Maurischat C. Return to work after myocardial infarction/ coronary artery bypass grafting: Patients' and physicians' initial viewpoints and outcome 12 months later. Soc Sci Med. 2001;52(9):1441-50, http://dx.doi.org/10.1016/S02779536(00)00250-1.

13. Maeland JG, Havik OE. Return to work after a myocardial infarction: The influence of background factors, work characteristics and illness severity. Scand J Soc Med. 1986;14(4):183-95.

14. Pashkow FJ, Dafoe WA. Clinical cardiac rehabilitation: A cardiologist's guide. 2 ed. Baltimore: Williams \& Willkins; 1999.

15. Maeland JG, Havik OE. Psychological predictors for return to work after a myocardial infarction. J Psychosom Res. 1987;31(4):471-81, http://dx.doi.org/10.1016/0022-3999 (87)90005-5.
16. Slebus FG, Jorstad HT, Peters RJ, Kuijer PP, Willems JH, Sluiter JK, et al. Return to work after an acute coronary syndrome: Patients' perspective. Saf Health Work. 2012;3(2): 117-22, http://dx.doi.org/10.5491/SHAW.2012.3.2.117.

17. O'Neil A, Sanderson K, Oldenburg B. Depression as a predictor of work resumption following myocardial infarction (MI): A review of recent research evidence. Health Qual Life Outcomes. 2010;8:95, http://dx.doi.org/10.1186/1477-7525-8-95.

18. Bhattacharyya MR, Perkins-Porras L, Whitehead DL, Steptoe A. Psychological and clinical predictors of return to work after acute coronary syndrome. Eur Heart J. 2007;28(2): 160-5, http://dx.doi.org/10.1093/eurheartj/ehl440.

19. Fiabane E, Argentero P, Calsamiglia G, Candura SM, Giorgi I, Scafa F, et al. Does job satisfaction predict early return to work after coronary angioplasty or cardiac surgery? Int Arch Occup Environ Health. 2013;86(5):561-9, http:// dx.doi.org/10.1007/s00420-012-0787-z.

20. Slebus FG, Kuijer PP, Willems JH, Sluiter JK, FringsDresen MH. Prognostic factors for work ability in sicklisted employees with chronic diseases. Occup Environ Med. 2007;64(12):814-9, http://dx.doi.org/10.1136/ oem.2006.031807.

21. Vogel AP, Barker SJ, Young AE, Ruseckaite R, Collie A. What is return to work? An investigation into the quantification of return to work. Int Arch Occup Environ Health. 2011;84(6):675-82, http://dx.doi.org/10.1007/s00420011-0644-5.

22. Kivimäki M, Forma P, Wikström J, Halmeenmäki T, Pentti J, Elovainio M, et al. Sickness absence as a risk marker of future disability pension: The 10-town study. J Epidemiol Community Health. 2004;58(8):710-1, http://dx.doi. org/10.1136/jech.2003.015842.

23. Stay-at-Work and Return-to-Work Process Improvement Committee. Preventing needless work disability by helping people stay employed. J Occup Environ Med. 2006;48(9):972-87, http://dx.doi.org/10.1097/01.jom.0000235915.61746.0d.

24. Soderman E, Lisspers J, Sundin O. Depression as a predictor of return to work in patients with coronary artery disease. 
Soc Sci Med. 2003;56(1):193-202, http://dx.doi.org/10.1016/ S0277-9536(02)00024-2.

25. Vasiliauskas D, Raugaliene R, Grižas V, Marcinkevičiene J, Jasiukevičiene L, Kubilius R, et al. [Return to work after coronary artery bypass surgery]. Medicina (Kaunas). 2008;44(11):841-7. Lithuanian.

26. Bradshaw PJ, Jamrozik K, Gilfillan IS, Thompson PL. Return to work after coronary artery bypass surgery in a population of long-term survivors. Heart Lung Circ. 2005;14(3):191-6, http://dx.doi.org/10.1016/j.hlc.2004.12.022.

27. Hällberg V, Palomäki A, Kataja M, Tarkka M. Return to work after coronary artery bypass surgery. A 10-year followup study. Scand Cardiovasc J. 2009;43(5):277-84, http:// dx.doi.org/10.1080/14017430802506601.

28. Simchen E, Naveh I, Zitser-Gurevich Y, Brown D, Galai N. Is participation in cardiac rehabilitation programs associated with better quality of life and return to work after coronary artery bypass operations? The Israeli CABG Study. Isr Med Assoc J. 2001;3(6):399-403.

29. Sellier P, Varaillac P, Chatellier G, d'Agrosa-Boiteux MC, Douard H, Dubois C, et al. Factors influencing return to work at one year after coronary bypass graft surgery: Results of the PERISCOP study. Eur J Cardiovasc Prev Rehabil. 2003;10(6):469-75, http://dx.doi.org/10.1097/01.hjr. 0000106837.97722.86.

30. Engblom E, Korpilahti K, Hämäläinen H, Rönnemaa T, Puukka P. Quality of life and return to work 5 years after coronary artery bypass surgery. Long-term results of cardiac rehabilitation. J Cardiopulm Rehabil. 1997;17(1):29-36, http://dx.doi.org/10.1097/00008483-199701000-00004.

31. Hämäläinen H, Mäki J, Virta L, Keskimäki I, Mähönen M, Moltchanov V, et al. Return to work after first myocardial infarction in 1991-1996 in Finland. Eur J Public Health. 2004;14(4):350-3, http://dx.doi.org/10.1093/eurpub/14.4.350.

32. Centers for Disease Control, National Center for Chronic Disease Prevention and Health Promotion, Division of Nutrition and Physical Activity. Promoting physical activity: A guide for community action. Champaign: Human Kinetics; 1999.

33. Haghjoo M. Pharmacological and nonpharmacological prevention of atrial fibrillation after coronary artery bypass surgery. J Tehran Heart Cent. 2012;7(1):2-9.

This work is available in Open Access model and licensed under a Creative Commons Attribution-NonCommercial 3.0 Poland License - http://creativecommons.org/ licenses/by-nc/3.0/pl/deed.en. 